\title{
ON THE CULTURE OF PHILOSOPHICAL DIALOGUE
}

\author{
Artur Ravilevich Karimov ${ }^{1}$ \\ Alexei Sergeyevich Guryanov ${ }^{2}$ \\ Mikhail Gennadyevich Khort ${ }^{3}$
}

\begin{abstract}
The article is devoted to intraphilosophy (and, accordingly, four types philosophical dialogue and those obstacles that threaten it. One of these obstacles seems to be the self-reflection of philosophers that philosophy itself is an insult and is only possible as an insult. They argue that philosophy, challenging the opinion of authorities or the majority, thereby carries an intellectual insult. In the course of the conceptual analysis of "insult" concept, we show that this point of intellectual discrimination) are distinguished: interdisciplinary, intradisciplinary, interschool, and intraschool. Overcoming of intellectual discrimination within philosophy is associated with the need to criticize intellectual arrogance and intellectual snobbery and the development of international and intra-national dialogue in philosophy.
\end{abstract} of view is wrong, since insulting requires unfair motivation. Nevertheless, the intellectual insult is present in philosophy in a different form. It is expressed in the disqualification of the opponent as a "non-genuine" philosopher. Such an intellectual attitude, when a certain philosophical position is declared genuine (authentic), and all others are not authentic, is called philosophical chauvinism. Four main forms of intellectual chauvinism in

Keywords: philosophical dialogue, insult, virtue epistemology, intellectual snobbism, intellectual chauvinism, ISUD.

\section{Introduction}

This article touches on such field of research as comparative philosophy. By comparative philosophy, we mean comparative studies of intercultural (and intracultural) relations

\footnotetext{
${ }^{1}$ Kazan Federal University, Russia. e-mail: arrkarimov@kpfu.ru. tel: +79178748869.

${ }^{2}$ Kazan State Power-Engineering University, Kazan State Medical University, Russia

${ }^{3}$ Kazan Federal University.
} 
and connections between philosophers.

A similar problem is most relevant for philosophy, since there is more or less uniformity in science, even in humanities, on what is considered the standard of scientific and academic in this discipline. Philosophers, on the other hand, disagree even on the question of what is considered the subject of philosophy and what its methodology should be. Due to such fundamental disagreements between philosophers, a misunderstanding arises and sometimes an insulting attitude towards each other. This problem is compounded by the fact that there has been a fragmentation of philosophical research field. This circumstance has both positive and negative consequences. As a positive point is that there is freedom of philosophical research in Russia, probably, as nowhere else. In the United States, Great Britain and continental Europe, there are quite strict philosophizing frameworks that put the researcher into the politics of magazines and publishing houses. The relationship between philosophers within this fragmented reality needs serious transformation. It is primarily about the need to establish a culture of dialogue and respectful attitude within philosophy itself.

One of the obstacles to this is the self-reflection of some philosophers, which is expressed in the fact that such a dialogue and respectful attitude are not at all regarded as something desirable or positive, but even vice versa. We believe that such self-reflection of philosophers deserves serious criticism. An example in this regard is the article by $\mathrm{K}$. Martynov, "Philosophy as an insult" [1]. Two theses are put forward in it. The first thesis is that philosophy is built as an insult. The second thesis arising from the first is that philosophy is possible only as an insult. To demonstrate these theses, the author gives various examples from the history of philosophy, when philosophers showed disrespectful or insulting attitude to the public or to each other. In the main part, we will show that despite the fact that the article talks about a really serious problem, one cannot agree with its general conclusion that philosophy can exist only as an insult.

\section{Methods}

As a methodology, the article uses the conceptual analysis method, characteristic of modern analytical 
philosophy. The article also relies on the methodology of virtue epistemology, in which the apparatus of normative ethics categories is used to characterize cognitive attitudes. An example of this article are the concept of intellectual snobbery, intellectual humility, intellectual chauvinism, etc.

\section{Results and Discussion}

What is an insult? K. Brinev states that "in linguistic expertology, the problem of insult qualification is perhaps one of the most obscure problems" [2]. In Russian, "to insult" and "feeling an insult" means "insulting", i.e. to sadden, to upset. Aristotle in "Rhetoric" defines insult as anger accompanied by pain. The English word "insult" means "attack", "assault", "type of damage" (cf. Russian "stroke"). In Latin, "insultare" literally means "Jump on something", i.e. contains the semantics of humiliation and affirmation of its superiority and dominance. Thus, the semantics of the term "insult" includes 1) an attack that is aimed to cause 2) a state of grief, sorrow and 3) to unify him, to assert one's superiority over him. An important component of the pragmatics of insult is its perlocutionary aspect: to insult means to perform some action or cause a certain state. ${ }^{1}$

Can truth be offensive? J. Nou believes that the answer to this question depends on who and in what form it is presented [3, pp. 17-18]. Suppose that someone tells an overweight person (above the medical norm) that he is fat. Is this the truth? Yes. Will this be an insult? It depends on who says it and under what circumstances. Obviously, the call "Hey fat!" on the street from a stranger will be considered an insult. On the other hand, if a loved one tactfully informs him that he is overweight and worried about his health, advises him to go on a diet or go to the gym, then such an appeal will most likely not be taken as an insult. Truth does not have to be offensive, but for this it must be presented by the right person in the right context with the right motivation. And here it is necessary to turn to intellectual ethics, which has recently been actively developed in the framework of such a trend as the epistemology of virtues.

First of all, what motivation can underlie insult? Firstly, since we are talking about philosophy, we are interested in a special case of insult, namely, intellectual insult. It can be 
carried out in two varieties: 1) direct humiliation through the denial of the subject's rationality, understanding, mental fullness, etc. and 2) indirectly through appropriation of the right to testify to the Truth uniquely.

Philosophers show intellectual courage, challenging authorities or the majority opinion. This quality can only be attributed to the list of intellectual virtues of its owner. In our dissertation we define intellectual courage as "overcoming not any fear, but only one that interferes with 1) the achievement of specifically cognitive goals; 2) in a specifically cognitive sense ... In this sense, Giordano Bruno, for example, is a double example - both of courage in the moral and in the intellectual sense. On the one hand, his position threatened his personal safety and life itself and in this regard required moral courage. On the other hand, it challenged the established intellectual tradition, the prevailing opinion and threatened his intellectual status, and therefore demanded intellectual courage" [5, pp. 312-313]. The motivation of intellectual courage does not carry insults, because, as we have defined above, it does not carry the desire for intellectual humiliation of an opponent or the assertion of one's own intellectual superiority.

Yet in what sense is philosophy really offensive? What is the intellectual insult in philosophy?

K. Martynov writes: "A philosopher who wants to offend another philosopher uses cunning tactics. The philosopher should argue that the other philosopher is not a real philosopher, because he thinks irrationally, and therefore, his philosophical project is not intelligible" [1]. It is important to distinguish this form from direct insult to the individual (argumentum ad personam). Here, rather, there is a wellknown sophisticated method of "poisoning a well", a form of disqualification of an opponent. Instead of substantively criticizing the views of this or that philosopher, he is simply declared as a fake, not genuine philosopher.

I believe that such a move in argumentation is a manifestation of intellectual arrogance and snobbery. Arrogance can be defined as the following attitude: I am superior to others in some ways, and this gives me the right to treat them without respect: "I am above you, therefore, I have the 
right." Arrogance becomes intellectual if the rights that a person ascribes to himself come from his intellectual abilities and relate to cognitive activity.

I suggest calling any statement of the form philosophical chauvinism: $\mathrm{x}$ - is a genuine (real, true) philosophy or $\mathrm{x}$ - is a true (genuine, real) philosopher.

There are four main forms of philosophical chauvinism: 1) disciplinary; 2) interdisciplinary; 3) interschool; 4) intraschool.

By disciplinary chauvinism, we mean a view that believes that only a certain philosophical discipline is a "genuine", "real" philosophy. In Western European philosophy, metaphysics (ontology) has long been considered such a discipline, a "philosophical prototype". G. Mayorov expresses this opinion when he writes: "We consider a philosophy that corresponds to its original idea, discovered by Pythagoras, developed by Socrates and finally clarified and implemented by Plato. In this sense, any genuine philosophy is Platonism" [6, p. 68]. He calls the great metaphysicians from Plato to Hegel the exponents of this main, or "sophia" line in philosophy. Moreover, according to Mayorov,
Aristotle is already a departure from this "original" line, since he was interested not in sophia, but in the episteme, i.e. the nature of accurate, scientific knowledge. Therefore, he is not considered as "true philosopher". In modern philosophy, such discrimination is manifested in the denial of "philosophical" discipline status such as gender philosophy, media philosophy and even social philosophy.

The second form of intellectual chauvinism in philosophy is intradisciplinary chauvinism. Within the framework of a discipline, it is asserted what can be considered this discipline and what not. For example, metaphysics claims to be true metaphysics and not; in epistemology - what is real epistemology and what is not, etc. For example, Popper actually denies belonging of such authors as Descartes, Kant, or Russell to epistemology, since they did not share his subjectless understanding of knowledge. In the work "Objective knowledge", Popper contemptuously called Descartes, Locke, Berkeley, Kant and Russell "the philosophers of opinion" (belief) for the fact that the latter "were engaged in research of our subjective opinions, their foundations and origin" [7, p. 109]. He declares the 
only scientific epistemology to be epistemology without a subject of knowledge, and epistemology with a subject of knowledge is forced out into the field of psychology, etc.

The third and most common form of intellectual chauvinism is interscholastic chauvinism. Some philosophical school is declared "true philosophy", and all other areas are deprived of this status. An example here is the mutual rejection between modern continental and analytical philosophy. Continental philosophers accuse analysts of logical-linguistic scholasticism, the "cowboy" style of philosophizing, when opponents "shoot" each other with endless arguments and counterarguments. Analytical philosophers blame the continental for the lack of clarity, the misuse of scientific terminology. N. Chomsky called French philosophy "cheap and corrupt" [8, p. 310.]. An open letter from leading analytical philosophers against Derrida being awarded the degree of Honorary Doctor of the University of Cambridge because his philosophy does not meet the standards of "clarity and rigor" [9] became famous.
The fourth type of intellectual discrimination that we propose to highlight is intra-school chauvinism. The point is that within a certain philosophical current or the teachings of a particular philosopher, a certain canon is established, which all supporters of this trend or interpreters of this philosopher should follow. Russian philosophers are well aware of the controversy over which Max is authentic: the Marx of the period of the "Economic and Philosophical Manuscripts of 1844" or the late Marx? Wittgenstein's followers argue about whether his interpretation is more authentic: positivistic or mysticalmetaphysical. Of course, these disputes will continue until the philosophy continues. But philosophers must realize when their position becomes intellectually chauvinistic, arrogant, snobbish and discriminatory in relation to other philosophical points of view. The fact is that philosophers should have shown much more intellectual modesty and intellectual humility in their discussions.

\section{Conclusions}


The semantics of the term "insult" are quite rich. At least four different phenomena can be distinguished: 1) challenge the opinion of the majority, or the opinion of power and authority; 2) a direct attack on a person, i.e. argumentum ad personam; 3) disqualification of an opponent, i.e. also a variety of argumentum ad hominem, which is called "well poisoning"; and 4) "pro and con," or "black or white," when the opponent's position must be either completely rejected or fully accepted. All these different types of insults require special analysis in relation to the practice of philosophical discussion. The provisions of this article are the following. Firstly, the thesis that philosophy is an insult is ambiguous. The second thesis that philosophy is only possible as an insult is equally ambiguous. In some sense, yes, in other senses, no. Secondly, a really noteworthy problem has been raised. It is the issue of an opponent disqualification as a technique in philosophical discussion. In our opinion, it is the disqualification of the opponent that is the main obstacle to philosophical dialogue. We have analyzed the main forms in which this disqualification is carried out in modern philosophy. We put forward the normative thesis that the development of philosophical dialogue requires overcoming intellectual chauvinism in philosophy, i.e. discrimination in relation to various cultural, theoretical and methodological trends within philosophy.

\section{Summary}

The problem of philosophical dialogue culture, in contrast to the scientific one, is that philosophers are usually in a state of deep disagreement among themselves. From the point of view of the theory of argumentation, all disagreements can be conditionally divided into two groups $[10,16,17]$. The first group includes those types of disagreements that can be relatively easily resolved by a specific fact indication. Another type of disagreement concerns not facts, but the methods of establishing facts, and accordingly, beliefs about facts that are established by such methods. Researchers call the latter type "deep disagreement". The problem with the deep disagreement is that due to the fact that the opponents cannot find a common criterion to resolve a dispute, they resort to insults, disqualification of 
an opponent and other violations of argumentative ethics. This is precisely the fundamental basis for the culture of abuse in philosophy, which we discuss in this article. The way out of this situation should be a broader discussion of argumentative ethics quality. Even the fact that we refer to some epistemic attitude as intellectually virtuous or intellectually vicious (snobbish, chauvinistic) is already the first step towards creation the possibility of a philosophical dialogue between different traditions and trends. What are the ways to foster a culture of philosophical dialogue? This issue deserves special discussion. It seems that philosophers should set an example of philosophical dialogue culture. In modern philosophy, such an example is the activity of the International Society for International Dialogue (ISID) [11,14,15], which, together with the Polish Academy of Sciences, is also a co-founder of the journal Dialogue and Universalism [12,13]. ISID is an international philosophical community that regularly holds international congresses aimed to develop an international philosophical dialogue. The idea is to bring together philosophers from different countries
(USA, Europe, Asia, Africa) representing various philosophical traditions and philosophical movements in order to try to put this philosophical dialogue into practice. Since the author of this article has repeatedly participated in congresses held under the auspices of ISID, I would like to say responsibly that the meetings with representatives of philosophical thought from different countries and continents in the framework of such major philosophical forums can qualitatively reduce the degree of philosophical chauvinism and improve the culture of philosophical dialogue in modern world.

\section{Acknowledgements}

The work is performed according to the Russian Government Program of Competitive Growth of Kazan Federal University.

\section{References}

Martynov K. Philosophy as an insult // Domestic notes. No. 6 (63), 2014. [Electronic resource]: www.stranaoz.ru/2014/6/filosofiya-kak-oskorblenie. Access mode: free. 
Brinev K.I. The problem of expert assessment of an insult. Insult in the linguist's legal consciousness. Insult as a speech act // Linguistics in law. No. 1 (11), 2011 pp. 330-338

Neu J. Sticks and Stones. A Philosophy of Insult. Oxford University Press, 2009. Minnullina E.B. Social knowledge in discursive practice // Scientific notes of Kazan. university. Series Humanity. Science. - 2014. - V. 156, book. 1, pp. 106-114.

Karimov A.R. The essence and role of intellectual virtues in the cognitive process: the dissertation for the degree of Doctor of Philosophy: specialty 09.00.01. / A.R. Karimov. Kazan, 2018. $-415 \mathrm{p}$.

Mayorov G.G. Philosophy as the search for the Absolute. Theoretical and historical experiments. 3rd version - M: Librocom, 2012. - 416 p.

Popper K.R. Objective knowledge. The evolutionary approach. Translation from English by D.G. Lahuti. M.: Editorial URSS, 2002.
Chomsky N. Language and Politics. Ed. by C. P. Otero, 2004.

From Professor Barry Smith and others. [Electronic resource]: http://ontology.buffalo.edu/smith/varia/ Derrida_Letter.htm. Access mode: free.

Karimov A.R. Deep disagreement and argumentative virtues // Society: philosophy, history, culture. 2018. No. 1. pp. 15-20.

International Society for Universal Dialogue. [Electronic resource]: http://www.worldialogue.org/ Access mode: free.

Taysina E.A. Polish magazine "D\&U" the scientific forum for a universal dialogue of scientists // Philosophy, Science, Culture. The collection of scientific articles dedicated to the 60th anniversary of Professor A. A. Shestakov. Samara State University of Architecture and Civil Engineering. Samara, 2015. pp. 161-171.

Read [4] on the perlocutionary effects of discourse in social practice 
Rasooli, M., \& Abedini, M. (2017). The

Relationship between Organizational

Support and Job Satisfaction of Experts and Managers of Islamic Azad University of Qeshm and Subsidiaries (International Units, Medical, Sama, Hormuz and Khamir). Dutch Journal of Finance and Management, 1(2), 42. https://doi.org/10.29333/djfm/5818

Marques, B. P., Villate, J. E., \& Carvalho, C. V. (2018). Student Activity Analytics in an e-Learning Platfom: Anticipating Potential Failing Students. Journal of Information Systems Engineering \& Management, 3(2), 12.

Abdul Rahman, S. (2019). Example Construction as a Devise to Reveal Awareness of Calculus Integration. International Electronic Journal of Mathematics Education, 14(1), 233-241. https://doi.org/10.29333/iejme/3999

Bakhyt, S., Kalimbetov, B., \& Khabibullayev, Z. (2018). Possibilities of mathematical problems in logical thinking. Development of secondary education pupils. Opción, 34(85-2), 441-457 